\title{
THE OCULAR SURFACE AS PART OF THE MUCOSAL IMMUNE SYSTEM: CONJUNCTIVAL MUCOSA-SPECIFIC LYMPHOCYTES IN OCULAR SURFACE PATHOLOGY
}

\author{
HARMINDER S. DUA ${ }^{1}$, JOSE A. P. GOMES ${ }^{2}$, LARRY A. DONOSO ${ }^{2}$ and \\ PETER R. LAIBSON ${ }^{2}$ \\ Nottingham and Philadelphia, USA
}

\begin{abstract}
SUMMARY
The mucosal immune system includes mucus membranes of the gut, respiratory and urogenital tracts. Mucosa-specific, intraepithelial lymphocytes (IELs), that correspond to the suppressor/cytotoxic subset and also express the human mucosal lymphocyte antigen (HML-1), are a unique component of this system. We have recently demonstrated these cells in the human conjunctiva, establishing the ocular surface as an integral part of the mucosal immune system. In this study we examined the distribution of lymphocyte subsets, with particular attention to mucosa-specific lymphocytes, in two ocular surface disorders, namely conjunctival intraepithelial neoplasia (CIN) and ocular cicatricial pemphigoid (OCP). Cryosections of biopsy specimen were immunostained using a panel of monoclonal antibodies against different lymphocyte subsets. In CIN, the CD8/HML ratio was decreased (1 $\pm 0)$ and $\mathrm{CD8} / \mathrm{CD} 4$ ratio was reversed $(0.54 \pm 0.21)$. HML-1+ cells were distributed throughout the epithelial layers of dysplastic tissue. Biopsy specimens of OCP showed normal ratios of CD8/HML (1.4 \pm 0.16) but the $\mathrm{CD8} / \mathrm{CD} 4$ was low $(1.29 \pm 0.88)$. Association of HML-1+ cells with the basal layer of normal epithelium and with all layers of dysplastic epithelium suggests that expression of HML-1 antigen may be induced by actively dividing cells. HML-1+ cells may have a role in immune mechanisms associated with ocular surface disorders.
\end{abstract}

Mucosal tissues of the body have certain unique immunological features that distinguish them from the systemic immune system. Epithelial and lym-

From: ${ }^{1}$ University Hospital, Queen's Medical Centre, University of Nottingham, Nottingham, UK; ${ }^{2}$ Wills Eye Hospital, Thomas Jefferson University, Philadelphia, Pennsylvania, USA.

Correspondence to: H. S. Dua, Chair and Professor, Department of Ophthalmology, B floor, South Block, University Hospital, Queen's Medical Centre, Nottingham NG7 2UH, UK. phoid cells that participate in immune responses of mucosal tissues belong to the mucosal immune system. Traditionally, the mucosal immune system is defined to include mucosa-associated lymphoid tissue (MALT) of the gastrointestinal tract (GALT), bronchial tree (BALT) and the urogenital tract. ${ }^{1}$ Significantly, the conjunctiva has not been included as part of the mucosal immune system. There are, however, several anatomical and functional similarlities between conjunctiva-associated lymphoid tissue (CALT) and GALT and BALT, suggesting that the conjunctival mucosa is an integral part of the mucosal immune system..$^{2-4}$

Conjunctival lymphocytes are dispersed within the epithelium and form a distinct layer in the substantia propria where, in places, they aggregate into follicles. The epithelium overlying the follicles is devoid of goblet cells, possesses elongated microvilli with few microplicae, and is modified to capture and present antigen. The intraepithelial lymphocytes are predominantly CD8+ $\mathrm{T}$ cells (suppressor/cytotoxic) while those in the substantia propria are CD8+ and CD4+ $\mathrm{T}$ cells (helper/inducer cells) in equal proportions. The substantia propria also contains a small proportion of B cells and mast cells. ${ }^{5,6}$ The distribution of $\mathrm{T}$ cell subsets and B cells in the conjunctiva is similar to that seen in the intestinal mucosa. In addition, the conjunctival epithelium has a large number of Langerhans cells and dendritic cells which also function as antigen-presenting cells. ${ }^{7}$ The conjunctiva thus possesses the capability to capture, process and present antigen to lymphocytes. It is generally believed that activated lymphocytes travel from the conjunctiva to regional lymph nodes (preauricular and submandibular) and from there enter the blood stream and gain access to the spleen. From the blood stream, by some as yet unknown homing mechan- 
Table I. Tissue specimens studied

\begin{tabular}{lccl}
\hline $\begin{array}{l}\text { Clinical } \\
\text { diagnosis }\end{array}$ & $\begin{array}{c}\text { Age } \\
(\mathrm{yr})\end{array}$ & Sex & Histopathological diagnosis \\
\hline CIN & 68 & M & CIN with moderate dysplasia \\
CIN & 40 & M & CIN with moderate dysplasia \\
CIN & 78 & M & CIN \\
CIN & 65 & M & Pyogenic granuloma; not CIN \\
CIN & 70 & M & $\begin{array}{l}\text { Hyperplastic conjunctiva with } \\
\text { keratinisation; not CIN }\end{array}$ \\
OCP & 45 & F & OCP \\
OCP & 56 & F & OCP \\
OCP & 38 & M & OCP \\
OCP & 60 & F & OCP \\
OCP & 64 & M & Non-specific changes, \\
& & & 'pseudopemphigoid' \\
\hline
\end{tabular}

CIN, conjunctival intraepithelial neoplasia; OCP, ocular cicatricial pemphigoid.

isms, these lymphocytes are thought to travel back to the conjunctiva and possibly to other mucosal tissues as well. ${ }^{2,3,6}$

In a recent study, we reported the presence of mucosa specific lymphocytes, bearing the human mucosal lymphocyte antigen (HML-1), in the normal human conjunctiva and lacrimal gland. ${ }^{8}$ The HML-1 protein is a $B 7$ integrin molecule. Integrins are surface proteins involved in adhesion of cells to extracellular matrix or in establishing cell-cell contacts. ${ }^{8,9}$ HML-1 positive (HML-1+) cells are also predominantly $\mathrm{CD} 8+$. They are unique to mucosal surfaces and have been abundantly demonstrated in the mucosa of the gastrointestinal and respiratory tracts. In the conjunctiva, they have a predominant intraepithelial location, just anterior to the basement membrane, along the laterobasal surfaces of the basal epithelial cells. ${ }^{7}$ Only $1-2 \%$ of peripheral blood lymphocytes express the HML-1 antigen. ${ }^{9-12}$

Functionally these intraepithelial lymphocytes (IELs) are believed to represent a distinct subpopulation of lymphocytes that may have special functions in immunological defence and tolerance mechanisms that operate at mucosal surfaces ${ }^{9}$ and may also modulate some epithelial cell functions. ${ }^{4}$ HML-1 antigen may serve as a cell surface adhesion molecule that would interact with proteins expressed on the surface of epithelial cells and adjacent basement membrane allowing for specific mucosal homing and localisation of these cells. ${ }^{9,13}$ It has been established that adaptive immune mechanisms in MALT ${ }^{14-17}$ and CALT ${ }^{18}$ selectively suppress, rather than enhance, immune responsiveness to antigens encountered by mucosal surfaces. Since HML-1+ lymphocytes belong to the suppressor/ cytotoxic $(\mathrm{CD} 8+)$ subset, it is believed that these mucosa-specific lymphocytes may play a significant role in tolerance induction. ${ }^{14}$

Abnormal reactivity of mucosa-specific IELs may play a part in the pathogenesis of inflammatory and neoplastic diseases of mucous membranes. Hyperplasia of intestinal IELs has been noted in coeliac disease, coeliac-disease-associated $\mathrm{T}$ cell lymphomas, collagenous colitis, tropical sprue, giardisis and mild graft-versus-host disease. ${ }^{4}$ In gastrointestinal carcinomas, however, the proportion of IELs was found to be similar to that found in normal intestinal epithelium. $^{19}$

The response of conjunctival IELs in inflammatory and neoplastic conditions of the conjunctiva has not been studied. 'In this study we examined the proportions and distribution of IELs in conjunctival intraepithelial neoplasia (CIN) and ocular cicatricial pemphigoid (OCP). Furthermore, we mapped the distribution of other lymphocyte subsets in these conditions. The immune architecture of CIN with regard to lymphocyte subsets has not previously been described.

\section{METHODS}

Biopsy specimens from 5 patients with clinically diagnosed CIN and 5 patients with OCP were studied. Clinical details of the patients are given in Table I. In addition, 5 necropsy specimens from 'normal' donor cadavers were studied and used as controls. All specimens were transported to the laboratory in a moist airtight container, spread onto cucumber pieces and snap frozen as described previously. 8,20

Five micrometer thick serial cryosections of tissue were spread onto glass slides and stained with a panel of monoclonal antibodies against different lymphocyte subsets (Table II), using the alkaline phosphatase anti-alkaline phosphatase (APAAP) technique. ${ }^{8}$ HML-1+ cells were identified using Ber-ACT8 monoclonal antibody, which is a mouse monoclonal antibody against the HML-1 antigen. This antibody has been well characterised and details previously published. ${ }^{12}$ Briefly, Ber-ACT8 is known to specifically stain mucosal intraepithelial CD8 + T lymphocytes in the gut and bronchus. Ber-ACT8 reacts with $1-3 \%$ of fresh, peripheral blood CD8+ T cells, but not with peripheral blood granulocytes, monocytes, CD4+ T cells and B cells. Ber-ACT8 stains more than $90 \%$ of IELs and $20-50 \%$ of lamina propria T cells in the small intestine and bronchial epithelium. It has also been shown that most Ber-ACT8 positive cells are also CD8 positive. ${ }^{12}$ Positive, red-stained cells, were counted through an entire section at a magnification of $\times 400$ by two independent observers

Table II. Panel of monoclonal antibody markers for T-cell subsets

\begin{tabular}{lll}
\hline Antigen specificity & Clone & Source \\
\hline CD3 & UCHT1 & Dako Corporation \\
CD4 (helper/inducer) & OKT4 & Ortho-diagnostics \\
CD8 (suppressor/cytotoxic) & OKT8 & Ortho-diagnostics \\
CD22 (B lymphocytes) & 4KB128 & Dako Corporation \\
HML-1 & Ber-ACT8 & Dr R. Schwarting \\
\hline
\end{tabular}

${ }^{\mathrm{a}}$ This antibody was used in 1:50 dilution. All other antibodies were used in 1:100 dilution. 


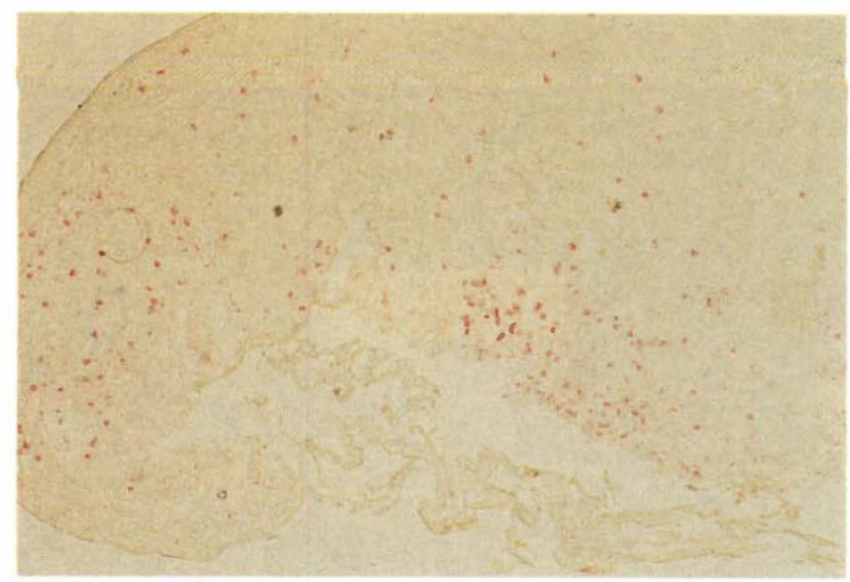

(a)

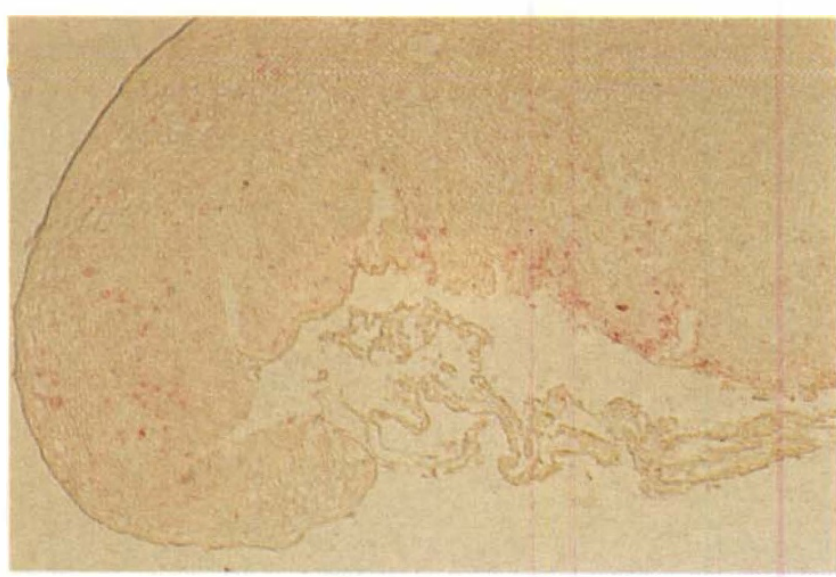

(b)

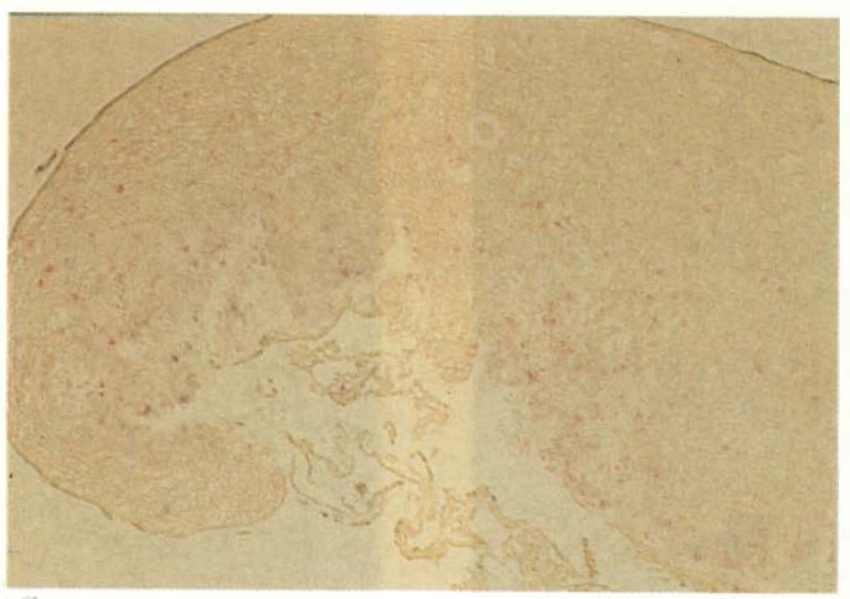

(c)

Fig. 1. (a) Cryosection of a specimen of CIN immunostained for CD4+ (helper/inducer) T lymphocytes. CD4+ cells are present in large numbers (APAAP OKT4, counterstained with haematoxylin, $\times 100)$. (b) Serial cryosection of same specimen of CIN as in (a), immunostained for CD8+ (suppressor/cytotoxic) $T$ lymphocytes. CD8+ cells are less numerous than CD4+ cells $($ APAAP OKT8, counterstained with haematoxylin, $\times 100)$. (c) Serial cryosection of same specimen of CIN as in $($ a), immunostained for $H M L-1+$ intraepithelial $T$ lymphocytes. $H M L-1+$ and $C D 8+$ cells are present in similar numbers $(A P A A P$ Ber-ACT8, counterstained with haematoxylin, $\times 100)$.

and averaged. Although sizes of serial sections of a given specimen were similar, section sizes differed from one specimen to the other. Comparisons between absolute cell counts could therefore not be made and ratios of $\mathrm{CD} 8+$ cells to $\mathrm{CD} 4+$ cells and CD8+ cells to HML-1+ cells were used. These ratios were not affected by size of sections.

\section{RESULTS}

Results of the cell counts in normal conjunctiva and in CIN and OCP are given in Table III. Although absolute cell counts varied from specimen to specimen, relative proportions of the different cell subsets were fairly constant and consistent.

\section{Conjunctival Intraepithelial Neoplasia (CIN)}

The diagnosis of CIN could be histopathologically confirmed in only 3 of the 5 biopsy specimens taken from patients with clinically diagnosed CIN. In 1 patient the histology was that of a pyogenic granuloma and in the other it showed a hyperplastic reaction with keratinisation. Proportions of cell subsets from the latter two were similar to that of normal conjunctiva and were excluded from the study. One striking observation was the marked increase in intraepithelial CD4+ lymphocytes in CIN (Fig. 1a). The ratio of intraepithelial CD8+/CD4+ cells was $0.54 \pm 0.21$, compared with $5.09 \pm 2.44$ in normals, and the difference was statistically significant $(p=0.02)$. The number of intraepithelial HML$1+$ cells was also increased. The CD8+/HML- $1+$ ratio was 1.00 , compared with $1.3 \pm 0.39$ in normals, and

Table III. Proportion of lymphocyte subsets in CIN, OCP and normals

\begin{tabular}{|c|c|c|c|c|}
\hline \multirow{2}{*}{$\begin{array}{l}\text { Tissue } \\
\text { specimen }\end{array}$} & \multicolumn{2}{|c|}{$\mathrm{CD} 8+/ \mathrm{CD} 4+$} & \multicolumn{2}{|c|}{ CD8+/HML-1+ } \\
\hline & $\mathrm{IE}$ & SP & IE & SP \\
\hline$\overline{\mathrm{CII}}$ & $0.54 \pm 0$ & $0.54=$ & $1.0 \pm 0^{\mathrm{b}}$ & 10.3 \\
\hline OCP & $1.29 \pm 0.88^{\mathrm{c}}$ & $0.55 \pm 0$ & $1.4 \pm 0.16$ & $=5.11$ \\
\hline Normals & $5.09 \pm 2.44$ & $0.57 \pm 0.39$ & $1.3 \pm 0.50$ & $1.92^{\circ} \pm 0.63$ \\
\hline
\end{tabular}

$\mathrm{IE}$, intraepithelial cells; SP, substantia propria cells.

${ }^{\mathrm{a}} p=0.02,{ }^{\mathrm{b}} p=0.02,{ }^{\mathrm{c}} p=0.07$. All $p$ values are exact two-tailed (Mann-Whitney $U$-test). 


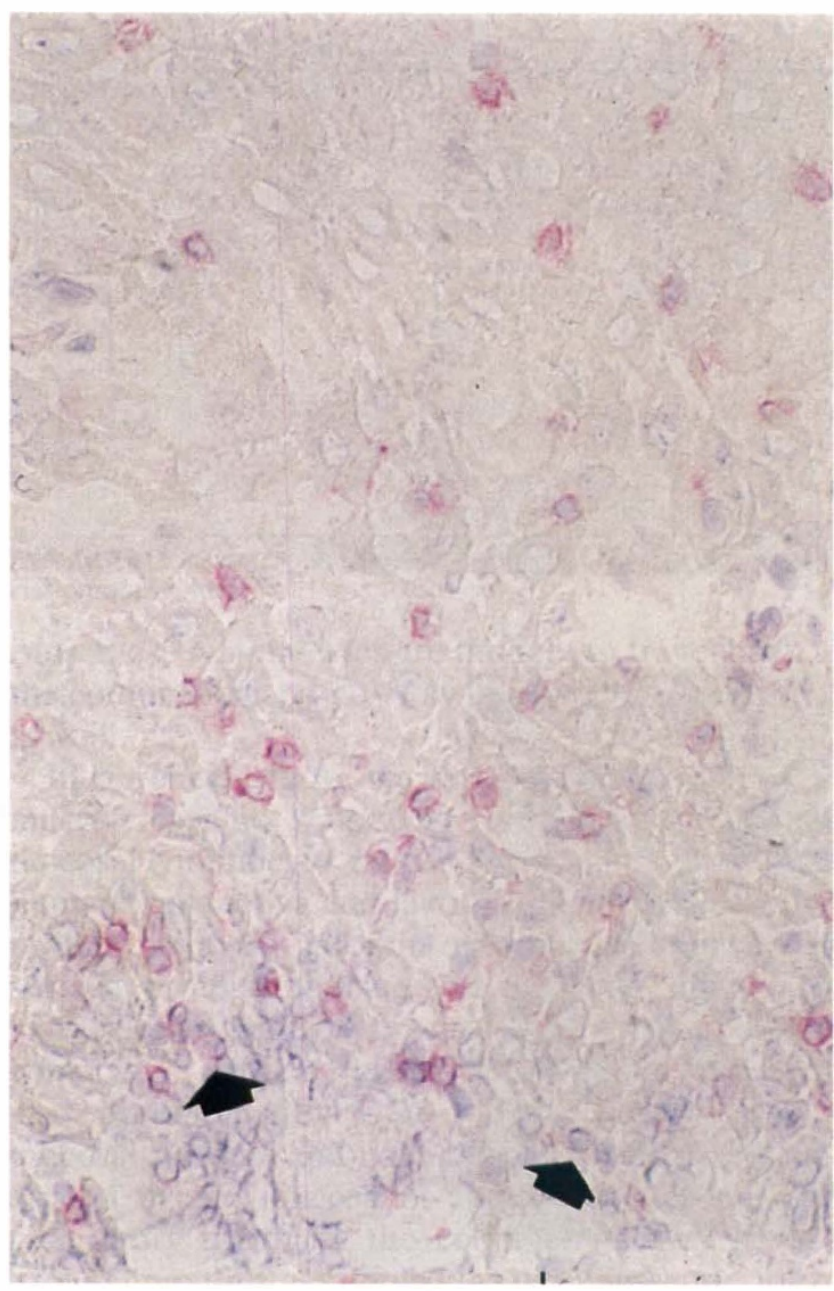

(a)

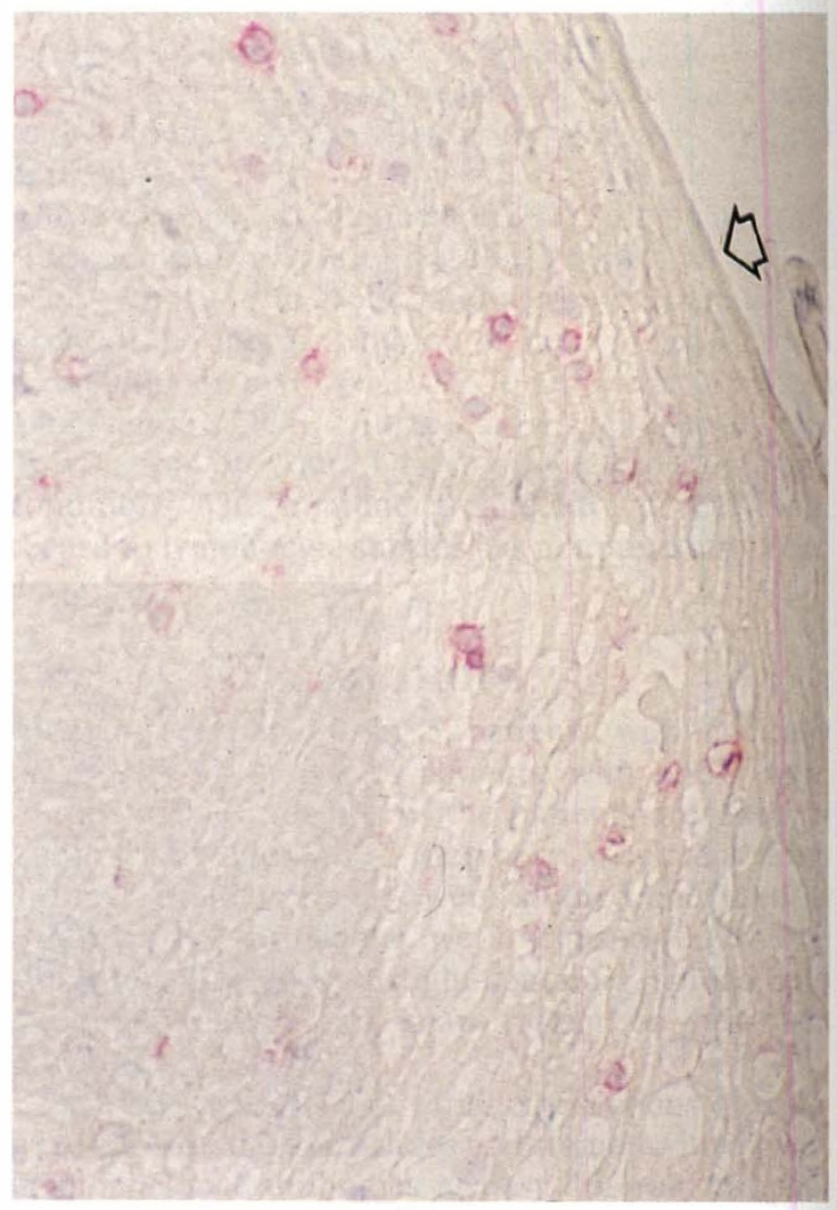

(b)

Fig. 2. (a) Cryosection of a specimen of CIN immunostained for HML-1+intraepithelial T lymphocytes. Note positively stained red cells distributed in suprabasal layers of epithelial cells. Arrows indicate basal layer of epithelial cells (APAAP BerACT8, counterstained with haematoxylin, $\times 400)$. (b) Cryosection of a specimen of CIN immunostained for HML-1+ intraepithelial $T$ lymphocytes. Note positively stained red cells distributed amongst epithelial cells right up to the surface (box arrow) of the tumour (APAAP Ber-ACT8, counterstained with haematoxylin, $\times 400)$.

the difference also reached statistical significance $(p$ =0.02) (Fig. 1b, c). Whereas HML-1+ cells were distributed predominantly among the basal epithelial cells of normal conjunctiva, they were found dispersed through all layers of neoplastic/dysplastic epithelium (Fig. 2a, b). In the substantia propria, although there was an increase in the CD8+ and CD4+ cells, the ratio of these cells remained normal. The CD8+/HML-1+ ratio in the substantia propria was significantly increased, indicating an excess of CD8+ cells which did not express the HML-1 antigen. In one specimen, a marked lymphocytic reaction (CD8+ and $\mathrm{CD} 4+)$ could be seen around a blood vessel located in the substantia propria adjacent to the basement membrane. Only an occasional cell in this infiltrate was positive for the HML-1 antigen (Fig. 3a, b). The number of B cells in relation to tumour tissue were insignificant. In the normal conjunctiva adjacent to tumour tissue, the distribution of lymphocyte subsets including HML-1 cells followed a normal pattern.

\section{Ocular Cicatricial Pemphigoid (OCP)}

Absolute numbers of cells in the conjunctival epithelium varied according to the degree of keratinisation. Lymphocytes were distributed among the basal and suprabasal cells (Fig. 4a) but were sparse to absent towards the parakeratinised and keratinised epithelium nearer the surface. The distribution of HML-1+ IELs followed a similar pattern. There was an increase in the number of lymphocytes in the substantia propria. These cells were distributed predominantly in fibrovascular fronds that extended between epithelial folds (Fig. 4b). In the epithelium, CD4+ cells were in excess of normal with the $\mathrm{CD} 8+/ \mathrm{CD} 4+$ ratio being $1.29 \pm 0.88$ $(p=0.07)$ and the CD8+/HML-1+ ratio was not significantly altered $(1.4 \pm 0.16)$. In the substantia propria, the $\mathrm{CD} 8+/ \mathrm{CD} 4+$ ratio was normal but the CD8+/HML-1+ ratio was increased (4.9 \pm 5.1$)$ reflecting the increase in $\mathrm{CD} 8+$ cells without a corresponding increase in expression of the HML-1 antigen. 


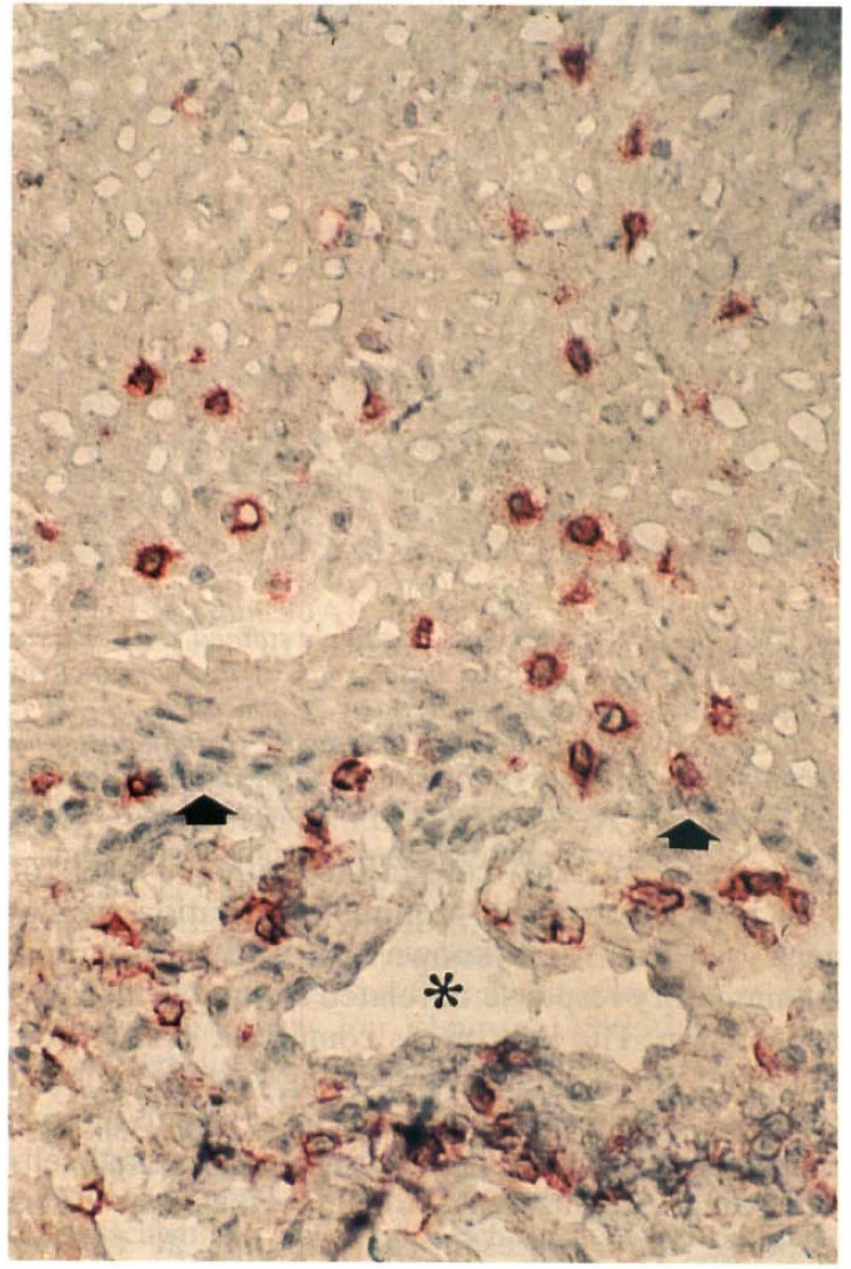

(a)

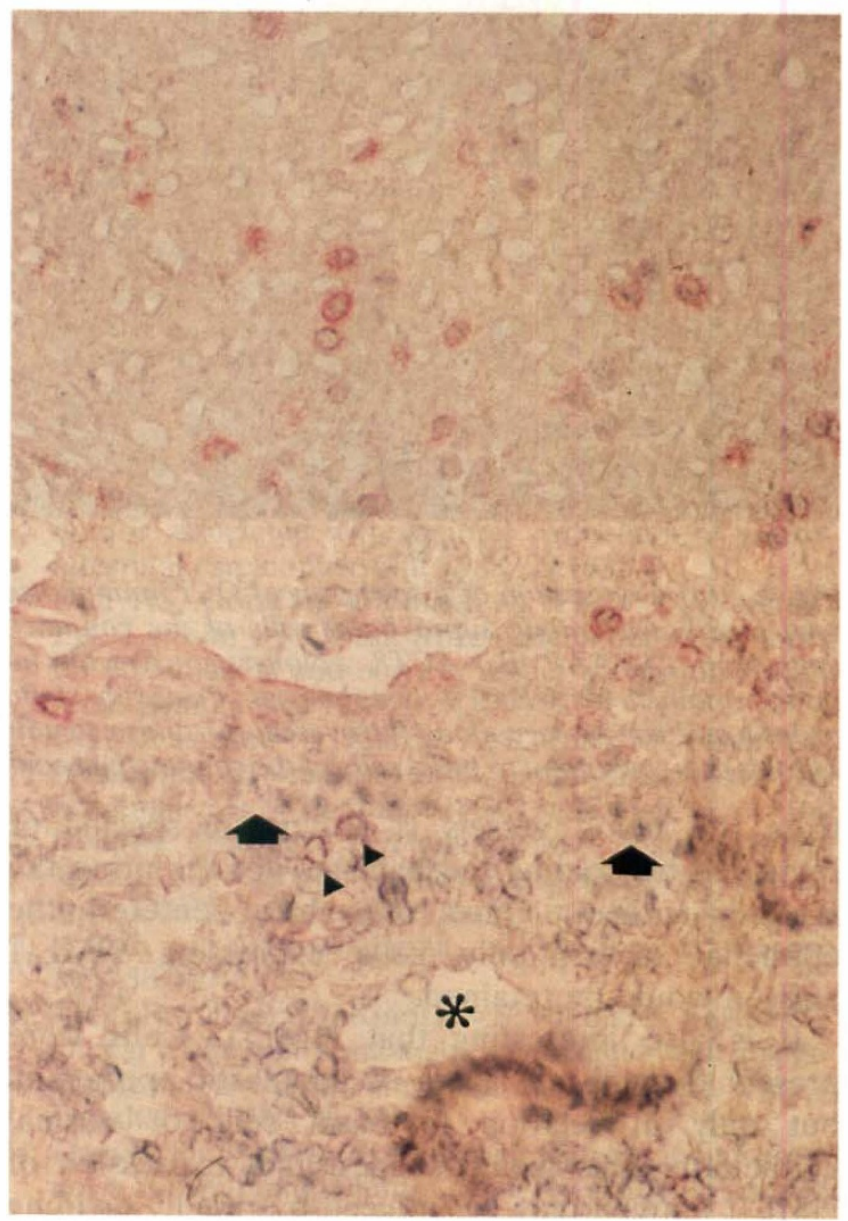

(b)

Fig. 3. (a) Cryosection of a specimen of CIN immunostained for CD8+T lymphocytes. Note the large number of positive cells around a blood vessel in the substantia propria of the tumour. Asterisk indicates lumen of blood vessel and arrows point to basement membrane of epithelium (APAAP OKT8, counterstained with haematoxylin, $\times 400)$. (b) Serial cryosection of same specimen of $C I N$ as in (a), immunostained for HML-1+T lymphocytes. There are a large number of mononuclear cells around a blood vessel in the substantia propria of the tumour but only an occasional cell (arrowheads) is positive for the $H M L-1$ antigen. Numerous cells positive for the HML-1 antigen are present in the epithelial layers of the tumour. Asterisk indicates lumen of blood vessel and arrows point to basement membrane of epithelium (APAAP Ber-ACT8, counterstained with haematoxylin, $\times 400)$.

\section{DISCUSSION}

The demonstration of HML-1+ mucosa-specific lymphocytes in the human conjunctiva and its ability to induce tolerance against encountered antigens clearly suggests that the conjunctiva is an integral part of the mucosal immune system. It is generally accepted that mucosa-specific IELs participate in defence mechanisms against microorganisms, tolerance induction against environmental allergens and modulation of epithelial cell function. ${ }^{19,21}$ However, the exact role of HML-1 antigen is not known. Besides enabling cell-cell and cell-extracellular matrix communications, it has been implicated in specific homing of these lymphocytes to mucosal tissue. It has been hypothesised ${ }^{9,13}$ that naive lymphocytes express a variable number of relatively non-specific homing receptors. Once a lymphocyte is activated in a particular tissue, cellular interactions within the microenvironment of that tissue may upregulate the expression of adhesion receptors specific for that tissue. At the same time expression of other adhesion receptors may be down-regulated. Such an increase in specific adhesion receptors would allow that lymphocyte to specifically home to, or function in, the given tissue. HML-1 antigen may represent such a mucosa-specific adhesion receptor.

It is interesting to note that in one specimen of CIN where a large number of CD8+ lymphocytes were present around a blood vessel in the substantia propria, only an occasional cell was positive for the HML-1 antigen. However, within the epithelium, almost all CD8+ cells also expressed the HML-1 antigen. This would indicate that any participation of HML-1 antigen in homing mechanisms would become relevant only after the cells have left the vessels and entered the intraepithelial environment. One would have to postulate that the exodus of cells 


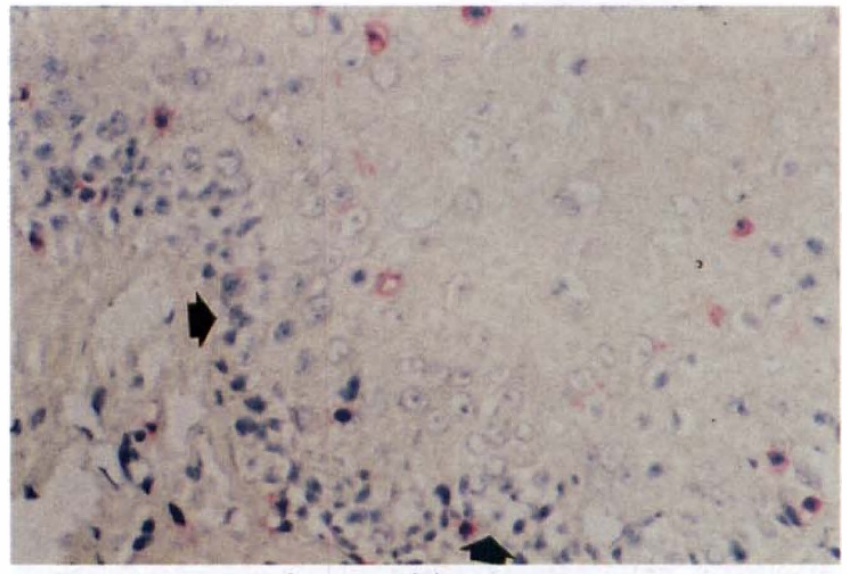

(a)

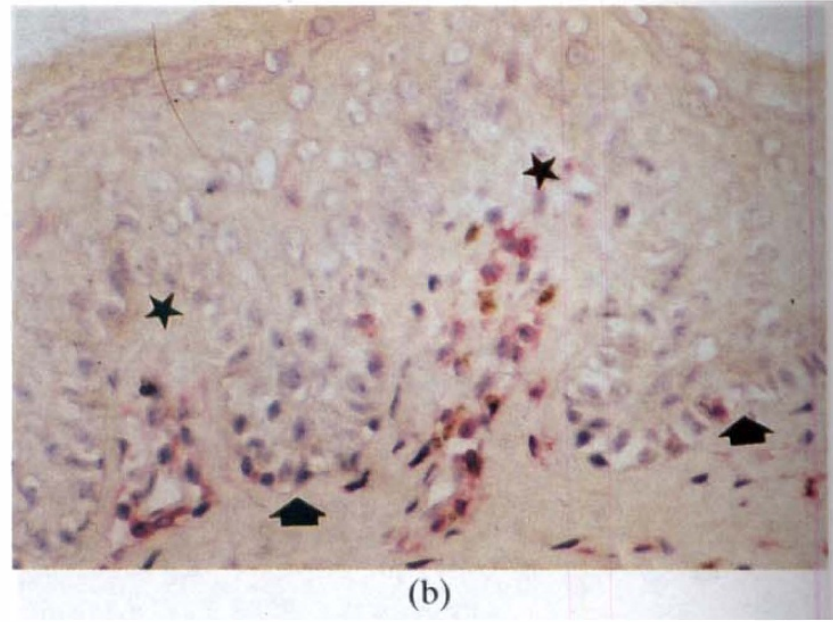

(b)

Fig. 4. (a) Cryosection of a specimen of OCP immunostained for HML-1+T lymphocytes. Positively stained red cells are seen distributed among supra basal cells of the conjunctival epithelium. Arrows point to basal cells of the conjunctival epithelium (APAAP Ber-ACT8, counterstained with haematoxylin, $\times 400)$. (b) Cryosection of a specimen of OCP immunostained for CD4+ $T$ lymphocytes. Positively stained red cells are seen distributed predominantly in the substantia propria and can be seen along fibrovascular fronds extending between folds of the basal epithelium (asterisks indicate summit of folds). Arrows point to basal cells of the conjunctival epithelium (APAAP OKT4, counterstained with haematoxylin, $\times 400)$.

from the blood vessels is either non-specific or regulated by homing mechanisms not requiring the HML-1 antigen. Once cells have entered the epithelial layers, only cells expressing HML-1 antigen would be retained.

It is also interesting that HML-1+ cells were present through all layers of neoplastic epithelium but only in relation to basal cells of normal epithelium. This would suggest that expression of HML-1 antigen may be induced by rapidly dividing cells. The cytokine TGFB (transforming growth factor) is known to enhance the expression of HML-1 antigen on CD8+ lymphocytes. ${ }^{9}$ It has also been demonstrated that proliferating malignant cells produce excess of TGFB. ${ }^{22}$ It is likely that neoplastic conjunctival cells produce excessive amounts of TGFß which in turn induces the expression of HML-1 antigen on CD8+ lymphocytes. Similarly, the presence of HML-1+ cells among basal and suprabasal cells in OCP probably reflects the epithelial hyperplasia that occurs in this condition. ${ }^{23}$ Jarry et $a l^{19}$ studied the distribution of HML-1+ cells in the epithelium of gastrointestinal carcinomas and their metastases. They did not find any difference in the IEL population from normal gut epithelium and suggested that even though the numbers were the same, some interactions between lymphocytes and epithelial cells may not be maintained in tumour epithelium. The significant increase in HML-1+ cells in CIN noted in our study may be due to the tissue being dysplastic rather than frankly carcinomatous. Immunological dedifferentiation occurs in parallel with morphological dedifferentiation during carcinogenesis. ${ }^{24}$ This could explain a difference in the host immune response between early neoplastic change (CIN) and frank neoplasia (carcinoma).

The presence of a large number of CD4+ cells and the increase in CD8+ cells in the epithelial layers of CIN is of interest and requires explanation. Malignant tumours are known to elicit a chronic inflammatory response unrelated to tumour necrosis or infection. The infiltrate is comprised mainly of $\mathrm{T}$ cells and macrophages, indicating a cell-mediated response. This response may be partly due to tumour cells expressing antigens different from normal cells and being recognised as foreign by the host. ${ }^{25}$ This response may represent an attempt at tumour destruction or may just be an epiphenomenon.

Several studies have examined the humoral and cellular immune changes that occur in OCP with similar results. ${ }^{26,27}$ There is an increase in CD4+cells in the epitheluim with a decrease in CD8+/CD4+ ratio and an increase in both CD4+ and CD8+ cells in the substantia propria. There is also an increase in $\mathrm{B}$ cells and plasma cells. Our results were similar to the above but we also looked at the subset of HML-1 CD8+ cells. This subpopulation of cells did not show any significant change from normal, in the epithelium or substantia propria, suggesting that IELs do not participate in any significant manner in the immune responses that occur in OCP.

This work was supported in part by the Lions Eye Bank of Delaware Valley, Philadelphia. Gene Polgar, Executive Director.

Key words: Conjunctival intraepithelial neoplasia, Mucosal lymphocytes, Ocular cicatricial pemphigoid.

\section{REFERENCES}

1. Strober W, James SP. The mucosal immune system. In: Stites DP, Terr AI, editors. Basic and clinical immunology. 7th ed. Englewood Cliffs, NJ: Appleton and Lange/Prentice-Hall, 1991:175-86.

2. Chandler JW, Gillette TE. Immunologic defense mechanisms of the ocular surface. Ophthalmology 1983;90:585-91. 
3. Franklin RM, Remus LE. Conjunctival-associated lymphoid tissue: evidence for a role in the secretory immune system. Invest Ophthalmol Vis Sci 1984;25: 181-7.

4. Cerf-Bensussan N. Intestinal intraepithelial lymphocytes. Gastroenterol Clin North Am 1991;20:549-76.

5. Arffa RC. Immunologic characteristics of the ocular surface. In: Grayson's diseases of the cornea, 3rd ed. St Louis, MO: Mosby Year Book, 1991:438-42.

6. Sacks EH, Wieczorek R, Jakobiec FA, Knowles DM. Lymphocytic subpopulations in the normal human conjunctiva: a monoclonal antibody study. Ophthalmology 1986;93:1276-83.

7. Rodrigues MM, Rowden G, Hackett J, Bakos I. Langerhans cells in the normal conjunctiva and peripheral cornea of selected species. Invest Ophthalmol Vis Sci 1981;21:759-65.

8. Dua HS, Gomes JAP, Jindal VK, Appa AN, Schwarting R, Eagle RC, Donoso LA, Laibson PR. Mucosa specific lymphocytes in the human conjunctiva, corneoscleral limbus and lacrimal gland. Curr Eye Res 1994;13:87-93.

9. Parker CM, Cepek KL, Russell GJ, Shaw SK, Posnett DN, Schwarting R, Brenner MB. A family of $B 7$ integrins on human mucosal lymphocytes. Proc Natl Acad Sci USA 1992;89:1924-8.

10. Cerf-Bensussan N, Beque B, Gagnon J, Meo T. The human intraepithelial lymphocyte marker HML-1 is an integrin consisting of a $B 7$ subunit associated with a distinctive $\alpha$ chain. Eur J Immunol 1992;22:273-7.

11. Cerf-Bensussan N, Jarry A, Brousse N, LisowskaGrospierre B, Guy-Grand D, Griscelli C. A monoclonal antibody (HML-1) defining a novel membrane molecule present on human intestinal lymphocytes. Eur J Immunol 1987;17:1279-85.

12. Kruschwitz M, Fritzsche G, Schwarting R, Micklem K, Mason DY, Falini B, Stein H. Ber-ACT8: new monoclonal antibody to the mucosa lymphocyte antigen. J Clin Pathol 1991;44:636-45.

13. Yednock TA, Rosen SD. Lymphocyte homing. Adv Immunol 1989;44:313-78.

14. Sedgwick JD, Holt PG. Down-regulation of immune responses to inhaled antigen: studies on the mechanism of induced suppression. Immunology 1985;56:635-42.

15. Vrabec TR, Gregerson DS, Dua HS, Donoso LA. Inhibition of experimental autoimmune uveitis by oral administration of S-antigen and synthetic peptides. Autoimmunity 1992;12:175-84.
16. Forrester JV, Liversidge J, Dua HS, Dick A, Harper F, McMenamin PG. Experimental autoimmune uveoretinitis: a model system for immunointervention: a review. Curr Eye Res 1992;11(Suppl):33-40.

17. Dick AD, Cheng YF, McKinnon A, Liversidge J, Forrester JV. Nasal administration of retinal antigens suppresses the inflammatory response in experimental allergic uveoretinitis: a preliminary report of intranasal induction of tolerance with retinal antigens. $\mathrm{Br} \mathrm{J}$ Ophthalmol 1993;77:171-5.

18. Dua HS, Donoso LA, Laibson PR. Conjunctival instillation of retinal antigens induces tolerance. Ocular Immunol Inflam 1994;2:29-36.

19. Jarry A, Cerf-Bensussan N, Brousse N, Guy-Grand D, Muzeau F, Potet F. Same peculiar subset of HML-1+ lymphocytes present within normal intestinal epithelium is associated with tumoral epithelium of gastrointestinal carcinomas. Gut 1988; 29:1632-8.

20. Dua HS, Gomes JAP, Singh A, Eagle RC, Donoso LA, Laibson PR. Fresh-frozen cucumber as a mount for conjunctival and corneal tissue in cryomicrotomy. Arch Ophthalmol 1994;112:1139-41.

21. Cerf-Bensussan N, Quaroni A, Kurnick JT, Bhan AK. Intraepithelial lymphocytes modulate Ia expression by intestinal cells. J Immunol 1984;132:2244-52.

22. Kloen P, Jennings CL, Gebhardt MC, Springfield DS, Mankin HJ. Expression of TGF beta receptors, TGFß1 and TGFB2 production and autocrine control of growth in osteosarcoma cells. Int $\mathrm{J}$ Cancer 1994;58:440-5.

23. Thoft RA, Friend J, Kinoshita S, Nikolic L, Foster CS. Ocular cicatricial pemphigoid associated with hyperproliferation of the conjunctival epithelium. Am J Ophthalmol 1984;98:37-42.

24. Davidsohn I. Early immunologic diagnosis and prognosis of carcinoma. Philip Levine Award Address. Am J Clin Pathol 1972;57:715-30.

25. Rubin E, Farber JL. Pathology, 2nd ed. Philadelphia: JB Lippincott, 1988:185.

26. Frith PA, Venning VA, Wojnarowska F, Millard PR, Bron AJ. Conjunctival involvement in cicatricial and bullous pemphigoid: a clinical and immunopathological study. Br J Ophthalmol 1989;73:52-6.

27. Sacks EH, Jakobiec FA, Wieczorek R, Donnenfeld E, Perry H, Knowles DM Jr. Immunophenotypic analysis of the inflammatory infiltrate in ocular cicatricial pemphigoid: further evidence for a $\mathrm{T}$ cell-mediated disease. Ophthalmology 1989;96:236-43. 